\title{
Parent choice: child or career?
}

\author{
Irina Kulikovskaya*, Raisa Chumicheva, and Lyudmila Kudinova
}

Southern Federal University, 344006, Rostov-on-Don, Russia

\begin{abstract}
The article deals with the issues of global challenges that determine the systemic risks of family and childhood. The main risks are identified gaps in child-adult relationships, the parents' choice between career or family, ways to resolve personal and professional problems in a family. The models of parenting and the model of psychological and pedagogical support and family assistance to parents in questions of the professional implementation and upbringing of the child, the harmonization of parent-child relationships are described.
\end{abstract}

\section{Introduction}

The international community in the modern global world with its challenges and risks, the problems of parents choosing a career and family, career or child, cares about their future children. The world is changing and a new image of parents and a new image of the child as subjects of development, recognition of their rights to free self-development and cultural identification, integrity of life and the fullness of their lives with cultural meanings, are emerging. The question arises for scientists and parents: how to combine their professional self-development, career advancement and ensuring a happy childhood for a child, creating a happy family.

In a rapidly developing world, new spaces are being created and a new type of children is emerging that enters the second quarter of the XXI century, and these are children with a new consciousness, feelings, behaviors, means of communication. Different states strive to alleviate the situation of working parents by creating optimal conditions for them to manifest motherhood and realize their career:

in France, Denmark, Switzerland, if you have more than three children, then you are actually exempted from paying taxes, the society provides parents with the opportunity to combine their careers and raising their children without sacrificing their careers;

in Germany - the Maternity Protection Act (Mutterschutzgesetz) applies to all women in labor relations with full and part-time work (Future Research Foundation (Stiftung für Zukunftsfragen) by Professor Ulrich Reinhardt).

Modern parents face a dilemma: raising a child or building a career? How to become good parents if you are engaged in professional activities? There are also questions arising in education sphere: how to help parents in the upbringing and socialization of the child, in maintaining harmonious parent-child relationships in a situation where there is a variety of

\footnotetext{
* Corresponding author: iekulikovskaya@sfedu.ru
} 
parenting models, family types, parenting styles, and at the same time not to abandon a successful career?

\section{Wording of the problem}

In the process of studying the indicated problem, the team of authors proposed the following tasks:

1. To study contemporary socio-cultural challenges affecting parenthood.

2. To systematize parental models that have been developed in the new realities of modern life.

3. To develop and test a model of psychological and pedagogical support and family support as an integrated humanitarian technology for updating the personal resources of parents, a child, harmonizing child-adult communities and the need for each family member to achieve success (personal, social, career, etc.)

\section{Research methods}

Theoretical comparative analysis of scientific literature, content analysis of scientific literature, design and modeling.

\section{Cases of the parenthood phenomenon in modern challenges}

Parenting is defined as the cultural and historical value of relations with children, in this attitude the feelings of parents and children, parental roles in questions of their upbringing, practice of parental behavior as an example to follow, a combination of values and attitudes that form the children's life positions are manifested. Parents bear individual responsibility for their children, are aware of the need to invest material, social, cultural efforts, organize the life of the child and devote their free time to their development, worry about their future and provide conditions for their future happy lives. Global trends have led to the transformation of parenthood, the relationship of parents to children and mothers in choosing the path of self-development - in a professional career or family life.

\section{Case 1. "Modern challenges for parenthood"}

The crisis of the traditional model of family, parenthood, childhood and child-adult relations is expressed in the following main characteristics:

- the emergence of new models for parenthood - "one-child family", "single-parent family", "migrant family", "double-career family", where both parents are career-oriented, concerned about the material wealth of the family, parents do not have enough time to raise a child, the family is reduced communication and cooperation with children, the presence of a emotional warmth deficit, which leads to difficulties in the development of children to the spread of family distress;

- changes in child-adult relations - parents' cruel treatment of children and the presence of all forms of violence against children in the family, deviant behavior of spouses, the tendency to distance the father from the problems of raising a child, his low emotional involvement and orientation to parenthood;

- the growth of new risks associated with the dissemination of information, the creation of a digital environment that poses a danger to children and parent-child relationships, which leads to intensive primitivization of children's consciousness, the growth of cynicism, rudeness, cruelty, aggressiveness, the development of addictive behavior and, as 
a result, an increased level of anxiety children, insecurity, loneliness, fear, on the one hand, and infantilism, selfishness, spiritual emptiness, on the other hand.

The study by O. V. Kuchmaeva notes a legitimacy loss of the family institution, a change in motivation for family development and parenthood, and attitudes regarding the birth of children. The transformation of the youth worldview into parenthood and the actualization of career growth priorities is due to the emergence of new opportunities and socio-economic resources for the professional fulfillment of young people, to satisfy their career ambitions. Such a transformation prompts the state to search for new directions in the field of family policy, forms of preservation, ways of supporting and strengthening the prestige of the family, and recognition of the social and personal significance of family life. The value orientations and attitudes of young people toward self-realization in professional activity are a serious challenge not only for the individual person, but also for the state, its strategies regarding the development of the family institution in Russia, taking into account the mosaic pattern and the diversity of parenting patterns and the position of young people "not to have a baby in inconsistent with their values and attitudes". According to the results of an extensive study, O. V. Kuchmaeva comes to the conclusion that the current demographic situation - a decrease in the birth rate is due to the stable attitude of the respondents that the family and children are not significant for life and career success. Only those respondents who are not socially active have problems of social adaptation, are looking for opportunities to realize themselves in the family. This is also confirmed by the monitoring data of the Russian Central Executive Committee and V.G. Dobrohleb, E.A. Ballaeva, R. Lesthaeghe et al.

V.G. Dobrohleb, E.A. Ballaeva noted many multidirectional changes in family relations - the growth of traditionalism, the modernization of the family as an institution, the social degradation of family and family ties, the mismatch of family values, the imbalance of gender roles, and the decline in the quality of marital relations. These are the characteristics of the crisis as a challenge for the state and manifestations of parenthood, according to the authors, are determined by the "double burden" model: "women's professional work remains an important resource of the country's socio-economic development; professional employment of both spouses is the key to the well-being of a modern Russian family; traditional ideas about male and female destiny; "the spontaneous nature of the reforms associated with the transition to a market economy, etc." The woman's need to "sacrifice her family" and give preference to a career is connected, as shown by V.G. Dobrohleb, E.A. Ballaeva, with objective economic conditions - "one source of income is missing, a family with two working parents is the norm of modern Russian reality." Material incomes and health support ensure family viability and are seen as contemporary challenges of society.

Socio-economic challenges increase the requirements for the process of new generations' socialization, which enhances the importance of the family for the system of social interaction with the child, in the social situation of its development. However, according to V.G. Dobrohleb, E.A. Ballaeva, the modern family does not fulfill its social functions and does not always become resilient, but parents become career successful in their social professional group. This is due to the emergence of new challenges: environmental degradation; high risk of poverty; adaptation options; lack of new jobs; noncompliance of the social sphere with new requirements for the development of human potential; gender asymmetry, freedom of family-marriage relations, etc.

\section{Case 2. "Parental Risks"}

Among the many parental risks, I.S. Danilova identified the following: difficulties in the process of families' social adaptation to changes in society; the young age of the mother who does not see why her child is an object of social anxiety and state concern; postpartum 
depression; alcoholic parents, drug addicts who are not aware of their parental responsibilities; high level of stress instability; "Inadequate" attachment in a mother-child relationship, death of a loved one, prolonged hospitalization, health problems of parents, accident or serious illness of brothers and sisters. The author notes that in a single-parent family, the parent is faced with the problem of a lack of time necessary to communicate with their own children, a choice between personal, family and professional interests. There are increasing the number of mono-families, the possibility of ending a marriage and creating new relationships with another partner, combining children from different marriages, increasing the age of parents during childbearing, the possibility of combining parenthood with full-time employment, professional implementation by attracting professionals and delegating some of the parental functions to them. Personal individual values are put at the forefront, which, of course, affects not only the spiritual and moral state of society, but also on parent-child relationships in families. It can be assumed that with this development of events, so-called "civil" and "guest" marriages will become even more popular.

In a number of foreign articles, it is noted that a child brought up in a single-parent family is subject to pathological factors that disorganize socialization: changes in the rhythms of life, increased frequency of avoiding eye contact, instability of interests, desire for changeable and ambivalent interaction, behavior, actions, and attitude of community acceptance are weakly expressed, the acquisition of social knowledge and skills is slower; the frequency of using unbridled gestures (P. Straus, M. Manciaux). As a contradiction of modern parenthood, foreign authors have identified a "double challenge to society", which requires the simultaneous active participation of the mother in labor and professional activities and also active and constant participation in the life of the child, in satisfying his wants and needs for his socialization (R. Caledrón-Grossenbacher, S. Hays, R. Fibbi, J. Krummenacher, A. Lanfranchi, M. Spescha, P. Wanner).

\section{Case 3. "Support of parents as prevention of parental risks"}

Parental support is understood by us as a type of systemic activity in the prevention of parental risks and is represented by modules that are purposefully implemented in preschool educational organizations and the Southern Federal University.

The problem-diagnostic module is aimed at monitoring the problems and risks of the family, identifying children and adults and family relationships; on the diagnosis of individual problems of the child and their systematization in the map of observations; systematic monitoring of the psychological and pedagogical status of the child in the dynamics of his mental development; a description of the social and psychological portrait of modern models of parenthood and children in various categories of families.

The design and prognostic module is represented by various types of programs addressfully correlated with parenthood models:

- individual assistance programs for single-parent families, transnational families, migrant families and families for children with disabilities (preventive, correctionalpedagogical, psychological, rehabilitation);

- assistance by various specialists in the webinar mode, on-line and in real time to parents engaged in careers, businesses, affirmed in professional activities, the student family on health issues, education, socialization, child development, harmonization of family relations and relations with the child;

- event socialization program "A child with disabilities in the world of people" (corrective projects, social holidays, creative contests, etc.) of a child with disabilities, taking into account his personal, psychological, social problems of development and health 
status, as well as a program for correcting intra-family relationships that have developed as a result of having such a child;

- a program to accompany parents of a risk group and single-parent family "You are not alone", as a way of successful socialization for parents and a child, assisting psychologists in solving personal problems of parents through training;

- collaboration programs for parents with different parenthood models as a way of ensuring interaction, cooperation between specialists and parents to support their successful activities - professional and family, to form professional and methodological competencies, to update personal resources (prioritization of goals, values and needs, independence and initiative in the search for the meaning of life, awareness of the need for self-affirmation, etc.) by means of trainings, round tables, discussions, briefings.

The organizational and activity module, revealing the totality of activities and interactions of the preschool educational organization and the family:

- correctional and developmental activities aimed at supporting the health of the child (physical, psychological, social), ensuring effective conditions for the development, socialization and education of the child in the family;

- psychological and pedagogical group and individual counseling (joint activities, communications, trainings, exercises, etc.) based on the principle of partnership;

- adaptation and organizational activities with specialists and parents to create a trusting environment for communication and interaction with the child in the family (conversations, observations, trainings, etc.);

- psychological and pedagogical support of parents on the prevention of problems, conflicts in parent-child relationships;

- educational, providing conditions for parents to master modern methods of socialization and raising a child in the family.

The technological module, revealing a comprehensive humanitarian technology for supporting and helping the family to support the balance of professional and family activities, is characterized by:

- the lack of strict regulation of the parents' actions, the presence of "soft" sociopsychological and pedagogical work techniques "(technology of direct impact and increasing the intensity of positive changes in the personality of parents, indirect impact technology that ensures sustainability to changes in the development of motives, interests, and needs of parents);

- priority technology for collaborating with "free" partners on choosing a career or family, providing families with a higher standard of living, developing soft skills: the ability to prioritize, time management, the ability to recognize the emotions of other people (child, husband, etc.), shifts work as a financial risk for his family, planning work at home and in the office, changing the daily routine in connection with the socialization of the child, personal development in the family and family, organizing everyday life and ensuring "rearward", "life with the advent of the child", etc .;

- interactive technology of effective interaction with parents as legal representatives of the child and the main social customers in the context of a difficult social situation, attracting them to social partnership in accordance with state requirements and taking into account the individual development of the child and the differentiated model of parenting (structure, social status of the family, type and the style of family relations and education, the level of pedagogical culture) on the principles of trust, openness, mutual understanding;

- psychological and pedagogical support methods of parents (counseling, beliefs, conversations, pedagogical experimentation, analysis of problem situations, tips, interactive panels, etc.) aimed at supporting parents' faith in their positive aspects and personality advantages, opportunities (resistance to destructive external and internal factors) in creating optimal conditions for personal development, to harmonize family relationships, to prevent 
and overcome problems within the family and child development, to disclose taking the family's internal resources to solve problems, teaching the child to independently plan his life path and individual educational route, organize life activities, solve problem situations, and adequately respond to situations of his emotional discomfort;

- means of (display, demonstration, models) "cultivating" the child's abilities to find support in himself, "creating conditions in the family that contribute to successful social adaptation, rehabilitation and personal growth of the child and confirming his status in the family, promoting the development of the child's individually personal potential in various types of joint child-adult activity, taking into account its individual psychological characteristics, providing the child with the opportunity to deploy his life program along an individual trajectory in the social environment, in the world of culture, knowledge and opening another their "social soul", the search of their own "value fields", "social dimension" of self-realization in creative activities. (A.G. Asmolov).

\section{Conclusion}

The ongoing transformations in society, modern challenges, parental risks and family models require understanding of the new context of modern parenting - "the parent becomes more vulnerable, the child is the first victim of this parental insolvency", as well as the parental risks that have arisen in modern society under the influence of various social and economic calls, it is necessary to provide systematic assistance and support to parents in fulfilling parental functions and responsibilities, in solving personal, family's and professional problems that provoke parental risks.

\section{References}

1. I.S. Danilova, Parenthood risks and family vulnerability (literature review,/ Bulletin of new medical technologies, 24(4), 182-189 (2017)

2. O.V. Kuchmaeva, An ideal family model in the eyes of Russians and a strategy to increase the value of a family lifestyle. Economics and Management, 2, 70-82 (2019)

3. V.G. Dobrokhleb, E.A. Ballaeva, Family in the face of new social challenges, Population, 21(2), 60-68 (2018).

4. J. Elster, Explaining social behavior: more nuts and bolts for the social sciences (Cambridge University Press, 2015).

5. S. Hays, The Cultural Contradictions of Motherhhood (Yale University Press, Yale, 1996).

6. P. Wanner, R. Fibbi, M. Spescha, A. Lanfranchi, R. Caledrón-Grossenbacher, J. Krummenacher, Familles et migration. Etude sur la situation des familles migrantes et recommandations de la Commission fédérale de coordination pour les questions familiales (COFF, Berne, 2002).

7. I.E. Kulikovskaya, Axiological Sphere of Dialogue of Cultures: Phenomenon, Architectonics, Ontogenesis, World Applied Sciences Journal, 25(10), 1416-1422 (2013). ISSN 1818-4952 C IDOSI Publications, 2013 DOI: 10.5829 / idosi.wasj.2013.25.10.10.13421 